\title{
PENINGKATAN MANAJEMEN DAN TEKNOLOGI PEMASARAN PADA UMKM OJESA (OJEK SAHABAT WANITA) DALAM MENGATASI LESS CONTACT EKONOMI MASA COVID-19
}

\author{
Ruslaini, Abizar, Nina Ramadhani , Imam Ahmad \\ Universitas Muhammadiyah Lampung, Universitas Teknokrat Indonesia \\ rosiruslaini@uml.ac.id
}

\begin{abstract}
Ojesa (Ojek Sahabat Wanita) is an online motorcycle start-up business specifically targeted at women in Bandar Lampung. Like any other start-up business, Ojesa has experienced several obstacles, especially in management and application being used; these obstacles have been a more significant challenge during the Covid-19 period. Among the challenges were the absence of planning, organizing, actuating, and controlling (POAC) functions and the breakdown of the server, which made the drivers of Ojesa experienced obstacles in communicating with consumers. The activities' purposes were carried out to explore problems, find out the urgent, fewer contact problems in the economy during the Covid period, and conduct training and assistance in management and marketing technology. These activities have resulted in implementing the management function (POAC) in the activity and recording plan, and it eventually launched new products. The upgrade Ram is set unlimited so that the consumers' demands can be appropriately served, automatically, and real-time. There is a more integrated marketing technology development system. Also, there is an improvement in skills and management for its human resources to serve customers in a friendlier, more patient, and gentle manner. In the future, it is expected to have a solid team and professional human resources.
\end{abstract}

Keywords: Management, HR training, customer service improvement

\begin{abstract}
Abstrak
Ojesa (Ojek Sahabat Wanita) merupakan start up ojek online khusus wanita di Bandar Lampung. Dalam menjalankan usahanya Ojesa mengalami beberapa kendala, terutama aspek manajemen dan aplikasi yang di gunakan, kendala ini menjadi tantangan yang lebih besar dimasa Covid-19. Masalah yang ditemui adalah belum adanya penerapan fungsi-fungsi planning, organizing, actuating, dan controlling (POAC) dan server mengalami down sehingga Ojesa mengalami hambatan dalam berkomunikasi dengan konsumen. Metode kegiatan yang dilakukan adalah menggali masalah, ditemukan masalah urgent less contact ekonomi di masa Covid, di lakukan pelatihan serta pendampingan aspek manajemen dan teknologi pemasaran. Hasil dari kegiatan ini sudah ada penerapan Fungsi manajemen (POAC) pada rencana kegiatan, pencatatan Upgrade Ram menjadi unlimited sehingga permintaan konsumen bisa terlayani dengan baik, otomatis dan real time Sistem pengembangan teknologi pemasaran yang terintegrasi. Peningkatan skill dan manajemen yang baik bagi seluruh SDM sehingga melayani pelanggan dengan lebih ramah, lebih sabar dan lembut dan kedepan diharapkan akan terbentuk tim yang solid serta SDM yang professional.
\end{abstract}

Kata kunci: Manajemen, Pelatihan SDM, peningkatan layanan pelanggan 


\section{PENDAHULUAN}

Ojesa (Ojek Sahabat Wanita) merupakan start up ojek online khusus wanita di Bandar Lampung. Didirikan oleh dua wanita bernama Rani dan Yuli, mereka adalah sarjana di salah satu Universitas di Bandar Lampung. Dengan motivasi untuk memberikan solusi kepada para penumpang wanita yang ingin berpergian dengan aman dan nyaman tanpa perlu merasa khawatir dengan maraknya pelecehan seksual dan berbagai tindakan kriminal yang dialami wanita, maka Ojesa tampil sebagai solusi bagi para wanita dan anak-anak dibawah 11 tahun. Ojesa memiliki keunikan tersendiri karena seluruh dari manajemen, dan drivernya adalah semuanya berjenis kelamin perempuan/ wanita. Saat ini Ojesa memiliki sekitar 5 karyawan dan 300 driver wanita .

Dalam menjalankan usahanya Ojesa mengalami beberapa kendala, terutama sisi manajemen dan aplikasi yang di gunakan selama ini, kendala ini menjadi tantangan yang lebih besar dimasa Covid-19, tentuya hal ini pun hampir dialami oleh seluruh UMKM saat ini. George R. Terry sebagai Bapak manajemen dalam bukunya Principle of Manajemen menyebutkan manajemen adalah sebuah proses yang terdiri dari perencanaan, pengorganisasian, penggerakan, dan pengawasan untuk mencapai tujuan yang telah ditetapkan sebelumnya. Bahwa manajemen adalah suatu ilmu dan keterampilan yang di peroleh secara berproses dan memerlukan proses yang cukup untuk memahami serta perlu latihan untuk bisa menerapkannya. UMKM, masih lemah dalam kemampuan manajemen usaha, kualitas sumber daya manusia (SDM) yang masih terbatas, Pernyataan ini mendukung perjelasan dari pengabdian masyarakat terdahulu oleh Dewi Sartika Nasution bahwa kunci utama keberhasilan dalam mengembangkan usaha adalah pada manajemen pengelolaan usaha. Banyak usaha yang bangkrut karena pengelolaan usahanya yang kurang bagus. Tak peduli berapa banyak modal usaha yang dimiliki lama kelamaan akan habis juga jika tidak bisa mengelola dengan baik Bisnis seharusnya semakin lama akan semakin maju dan berkembang, hal ini tentunya perlu skill manajerial yang baik dan upaya menumbuhkan para karyawan/driver yang professional dan terbentuknya tim yang solid, serta di dukung dengan aplikasi teknologi pemasaran yang memadai, sehingga tujuan usaha akan tercapai dengan maksimal

Di masa Covid-19 Ojesa mengalami penurunan omzet yang drastis hal ini membuat Ojesa harus berpikir keras agar tetap mampu bertahan dan bisa tetap menjalankan usahanya, sebab Ojesa adalah salah satu sumber mata pencaharian para driver perempuan yang sebagian besar memiliki tanggungan keluarga. Oleh sebab itu diperlukan melakukan pelatihan dan pendampingan bidang manajemen dan Pemasaran pada Ojesa Lampung

Belum adanya penerapan fungsifungsi planning, organizing, actuating, dan controlling (POAC) agar dapat 
menggunakan sumberdaya yang terbatas dengan metode yang tepat sehingga pengelolaan dapat optimal untuk menghasilkan output perusahaan yang maksimal. Aplikasi Ojesa yang di download dari playstore belum berfungsi dengan maksimal karena server mengalami down sehingga Ojesa mengalami hambatan dalam berkomunikasi (konsumen-admindriver), Pada akhirnya Ojesa hanya menggunakan whatsapp dalam menjalakan ojek onlinenya.

\section{METODE}

Metode kegiatan yang akan dilakukan adalah menggali masalah, ditemukan masalah urgent less contact ekonomi di masa Covid-19 yaitu pada aspek manajerial dan aspek teknologi pemasaran pemasaran. Selanjutnya mencari solusi, ditemukan solusi untuk masalah Ojesa adalah dengan pelatihan dan pendampingan untuk masalah aspek manajerial serta perbaikan dan peningkatan aspek teknologi pemasaran oleh tim dan bekerjsama dengan berbagai pihak

\section{HASIL DAN PEMBAHASAN}

Program hasil kerja tim kami adalah aspek manajerial Ojesa ditargetkan mampu menerapkan fungsifungsi planning, organizing, actuating, dan controlling (POAC) dalam kegiatan bisnisnya. Aspek teknologi pemasaran ditargetkan Aplikasi Ojesa dapat digunakan untuk mendukung kegiatan bisnis dan Tim Ojesa mampu mengoperiskan aplikasi Ojesa.
Selanjutnya adalah produk kerja yang akan dilakukan adalah aspek manajerial berupa pelatihan, evaluasi, dan mentoring berkala dan berkelanjutan hingga Tim Ojesa dapat memperbaiki aspek manajerial Ojesa oleh tim. Aspek teknologi pemasaran berupa pembelian server, pendampingan penggunaan aplikasi Ojesa. Dalam hal ini mitra berpatisipasi dalam setiap tahapan pemberdayaan, seperti mengikuti pelatihan, evaluasi, dan mentoring selama proses pemberdayaan Ojesa berlangsung. Setelah program selesai, tim peneliti akan mendampingi Ojesa dalam mentoring agar pelaksanaan yang sudah dilakukan mendapat dampak signifikan terhadap Ojesa.

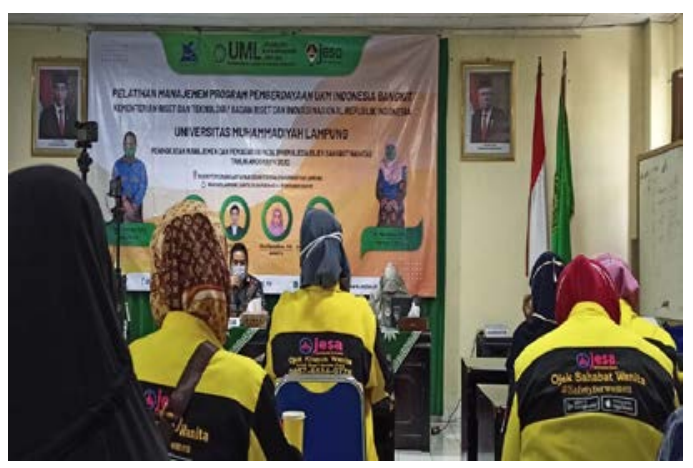

Gambar 1 Pelatihan POAC

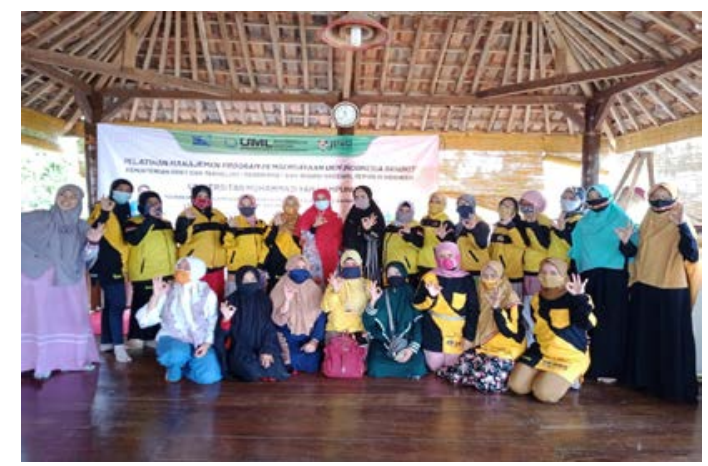

Gambar 2. Layanan Pelanggan 


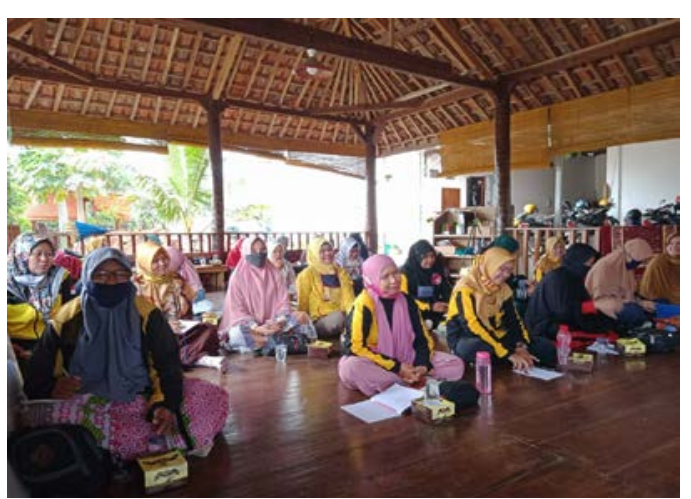

Gambar 3.Pelatihan dan pendampingan

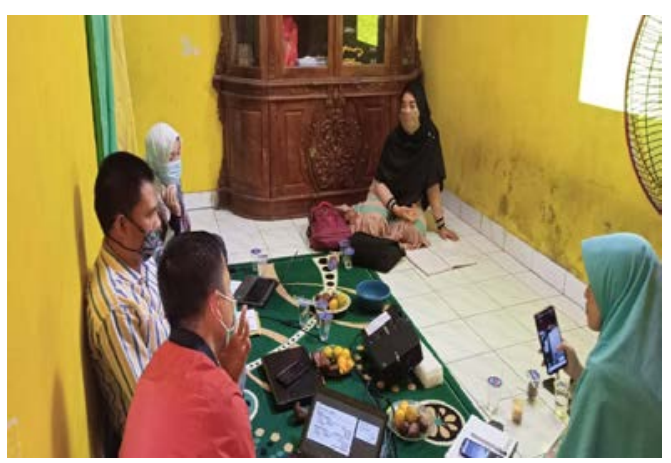

Gambar 4. Pendampingan POAC dan IT
Pelaksanan program yang diawali dengan memberikan pertanyanpertanyaan tentang manajerial kepada tim manajemen dan para driver, dilanjutkan dengan pelaksanaan pelatihan serta pendampingan aspek manajemen dan aspek teknologi pemasaran, kemudian dilanjutkan dengan tim mengadakan evaluasi setelah kegiatan berlangsung dan hasil kami peroleh ada pada 1.

Tabel . 1. Sebelum Pelatihan dan pendampingan PKM

\begin{tabular}{|c|c|c|c|}
\hline No & Perihal & $\begin{array}{l}\text { Sebelum } \\
\text { kegiatan }\end{array}$ & Keterangan \\
\hline 1 & $\begin{array}{l}\text { Pemahaman tentang kebutuhan } \\
\text { pasar, riset pasar dan peningkatan } \\
\text { strategi pemasaran }\end{array}$ & Kurang & $\begin{array}{l}\text { Omzet O-jesa dimasa covid-19 } \\
\text { mengalami penurunan drastis, karena } \\
\text { produk andalannya adalah abudemen } \\
\text { anak sekolah }\end{array}$ \\
\hline 3 & $\begin{array}{l}\text { Pemahaman tentang manajemen } \\
\text { (POAC) }\end{array}$ & Kurang & $\begin{array}{l}\text { Belum terbentuknya tim manajemen } \\
\text { yang solid serta memahami fungsi- }\end{array}$ \\
\hline 4 & Konsep pelayanan kepada pelanggan & Kurang & $\begin{array}{l}\text { fungsi manjemen untuk mencapai } \\
\text { tujuan usaha }\end{array}$ \\
\hline 5 & $\begin{array}{l}\text { Aplikasi tidak dapat di gunakan } \\
\text { karena server down }\end{array}$ & Kurang & $\begin{array}{l}\text { Driver yang belum memiliki skill } \\
\text { komunikasi yang baik saat } \\
\text { berkomunikasi kepada konsumen }\end{array}$ \\
\hline & $\begin{array}{l}\text { Belum memiliki data base server } \\
\text { yang terintegrasi }\end{array}$ & Kurang & $\begin{array}{l}\text { Menggunakan komunikasi lewat } \\
\text { WhatsApp sehingga tidak maksimal }\end{array}$ \\
\hline & & & $\begin{array}{l}\text { Hosting dan domain yang digunakan } \\
\text { masih dalam skala kecil, sehingga } \\
\text { membatasi ruang gerak ojesa dalm } \\
\text { menyimpan database konsumen serta } \\
\text { data lainnya }\end{array}$ \\
\hline
\end{tabular}


Tabel 2. Sesudah Diadakan Pelatihan Dan Pendampingan

\begin{tabular}{|c|c|c|}
\hline No & Perihal & Keterangan \\
\hline 1 & $\begin{array}{l}\text { Pemahaman tentang kebutuhan } \\
\text { pasar, riset pasar dan peningkatan } \\
\text { strategi pemasaran }\end{array}$ & $\begin{array}{l}\text { Omzet O-jesa dimasa covid-19 mulai mengalami } \\
\text { peningkatan sebesar } 20 \% \text { dari penurunan sebelumnya, } \\
\text { karena sudah melihat dan mengikuti kebutuhan pasar serta } \\
\text { peningkatan strategi pemasaran. Dengan diberlakukan } \\
\text { kebijakan pemerintah tentang New Normal, sehingga } \\
\text { layanan yang sempat di tutup kembali aktif hal ini seiring } \\
\text { dengan meningkatnya pemahaman dari tim Ojesa untuk } \\
\text { meningkatkan dan meluaskan Operasional Ojesa }\end{array}$ \\
\hline 2 & $\begin{array}{l}\text { Pemahaman tentang manajem } \\
\text { (POAC) }\end{array}$ & $\begin{array}{l}\text { Sudah ada penerapan Fungsi manajemen (POAC) pada } \\
\text { rencana kegiatan, pencatatan dan pelaporan omzet menjadi } \\
\text { lebih tertib, para driver menjadi lebih baik dalam melayani } \\
\text { pelanggan/penumpang, lebih sabar dan lebih lembut, } \\
\text { secara umum skill manjerial meningkat }\end{array}$ \\
\hline 3 & $\begin{array}{l}\text { Konsep pelayanan pelanggan kepada } \\
\text { pelanggan }\end{array}$ & $\begin{array}{l}\text { Para karyawan dan driver mulai memahami dan menyadari } \\
\text { pentingnya memberikan layanan yang cepat, ramah, sabar } \\
\text { dan menanamkan dalam setiap diri driver bahwa mereka } \\
\text { adalah representative dari Ojesa, }\end{array}$ \\
\hline 4 & $\begin{array}{l}\text { Aplikasi tidak dapat di gunakan } \\
\text { karena server down }\end{array}$ & $\begin{array}{l}\text { Upgrade Ram menjadi unlimited, sehingga permintaan } \\
\text { konsumen bisa terlayani dengan baik, otomatis dan real } \\
\text { time }\end{array}$ \\
\hline 5 & $\begin{array}{l}\text { Belum memiliki data base server } \\
\text { yang terintegrasi }\end{array}$ & $\begin{array}{l}\text { Dengan system pengembangan teknologi pemasaran yang } \\
\text { terintegrasi sehingga mempermudahkan komunikasi } \\
\text { antara konsumen, admin, driver }\end{array}$ \\
\hline
\end{tabular}

\section{KESIMPULAN}

Dari hasil kegiatan pelatihan dan pendampingan yang telah dilaksanakan ini dapat menjadi salah satu langkah dalam mengatasi less contact Economy dimasa Covid-19 bagi Ojesa, Dengan peningkatan skill dan manajemen yang baik sehingga akan terbentuk tim yang solid serta SDM yang professional. Terupgradenya server baru akan memudahkan komunikasi dan mempertemukan konsumen, admin, driver. Sehingga bisa meningkatkan layanan menjadi lebih baik, otomatis dan real time

\section{UCAPAN TERIMAKASIH}

\begin{tabular}{lcr}
\multicolumn{1}{c}{ Tim } & PKM & mengucapkan \\
terimakasih & kepada & Kementerian \\
Ristek-Brin & dalam & Program \\
Pemberdayaan & Masyarakat & UKM \\
Indonesia Bangkit atas bantuan dana \\
Pengabdian Masyarakat (PKM) tahun \\
2020 sehingga kegiatan PKM ini dapat \\
terlaksana dengan baik
\end{tabular}


DAFTAR PUSTAKA

Hasil wawancara pra pengabdian dengan pihak Manjemen Ojesa: Rani M, dikantor Ojesa, 25 Juni 2020

Sukarna, Dasar-Dasar Manajemen. Bandung: CV. Mandar Maju, 2011
Adiningsih, S., (2001), Regulasi dalam Revitalisasi Usaha Kecil dan Menengah di Indonesia, http://jurnal.unikom.ac.id/vol4/ art7.html, diakses tanggal 14 November 2019 